\title{
Small-caliber plastic stent for endoscopic ultrasound-guided drainage of a non-dilated pancreatic duct
}

Endoscopic ultrasound (EUS)-guided pancreatic drainage is increasingly utilized in cases where endoscopic retrograde cholangiopancreatography (ERCP) is not possible [1-3]. EUS-guided pancreatic drainage for a non-dilated pancreatic duct (PD) not only poses technical challenges but also increases the risk of procedure-related pancreatitis as well as stent-induced ductal injury. A small-caliber stent might be suitable for a nondilated PD to prevent ductal injury and upstream main duct obstruction, but there has been no report on a dedicated 5-Fr EUS-guided pancreatic drainage stent. Herein we present a newly designed 5-Fr plastic stent for EUS-guided pancreatic drainage (Through \& Pass Type IT; Gadelius Medical, Tokyo, Japan) ( Fig. 1), which is a thinner type of a previously reported stent [4].

A 75-year-old woman with a history of pancreatoduodenectomy for intraductal papillary mucinous neoplasm was hospitalized with a pancreatic fluid collection ( $>$ Fig. 2). The fluid collection did not subside after percutaneous drainage, and therefore we decided to perform EUS-guided pancreatic drainage ( Video 1). Under EUS guidance, we punctured the non-dilated main PD with a 19-gauge needle and inserted a 0.025-inch guidewire (-Fig.3a). The needle tract was dilated using an ultratapered mechanical dilator (ES dilator; Zeon Medical, Tokyo, Japan) and a 4-mmwide balloon dilator (REN; Kaneka, Osaka, Japan). Using a double-lumen catheter (Uneven Double Lumen Cannula; Piolax Medical Devices, Kanagawa, Japan), we successfully passed a 0.025 -inch hydrophilic guidewire into the jejunum and additionally inserted a 0.035 -inch guidewire to stabilize the scope position ("double guidewire technique”) ( Fig.3b) [5]. After dilation of the pancreaticojejunostomy anastomosis using the balloon dilator, a 5-Fr stent was readily positioned from the jejunum to the stomach

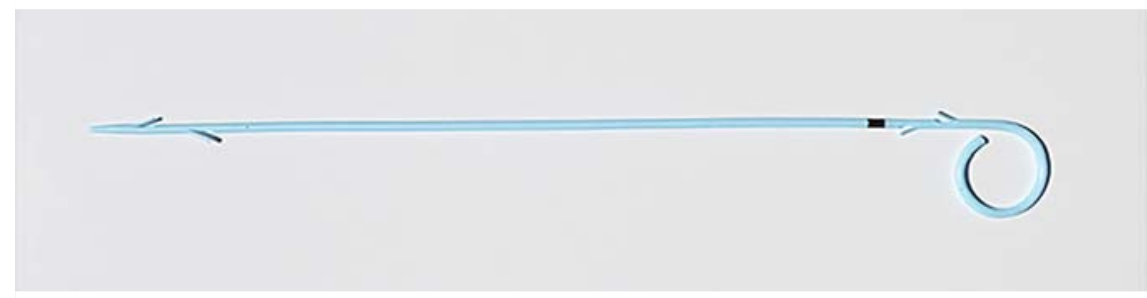

- Fig. 1 Newly designed 5-Fr pigtail plastic stent for endoscopic ultrasound-guided pancreatic drainage. The stent has a pigtail structure at one end and two flanges at each end to prevent migration. This stent was developed as a modification of the 7-Fr plastic stent designed for endoscopic ultrasound-guided drainage.

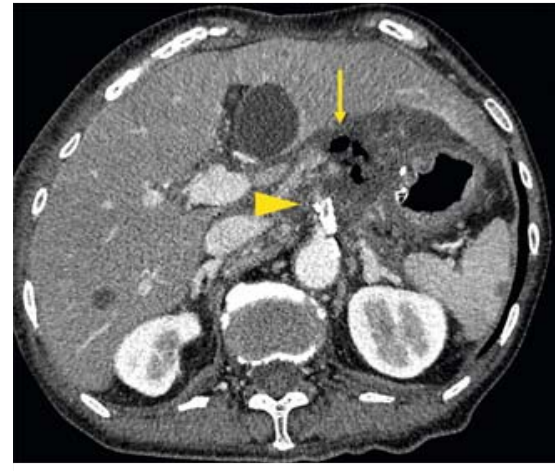

- Fig. 2 Contrast-enhanced computed tomography showing a fluid collection around the pancreaticojejunostomy anastomosis (arrow). An endovascular stent for celiac artery stenosis (arrowhead) is also shown.

( $\mathbf{F i g . 3 c}$ ). The postprocedural course was uneventful and the percutaneous drain was successfully removed. A follow-up CT scan 4 months later revealed the disappearance of the fluid collection without upstream ductal dilation.

Our new 5-Fr plastic stent was feasible in the EUS-guided drainage of a non-dilated PD.

Endoscopy_UCTN_Code_TTT_1AS_2AD

\section{Competing interests}

Dr. Itoi serves as a consultant of Gadelius Medical.
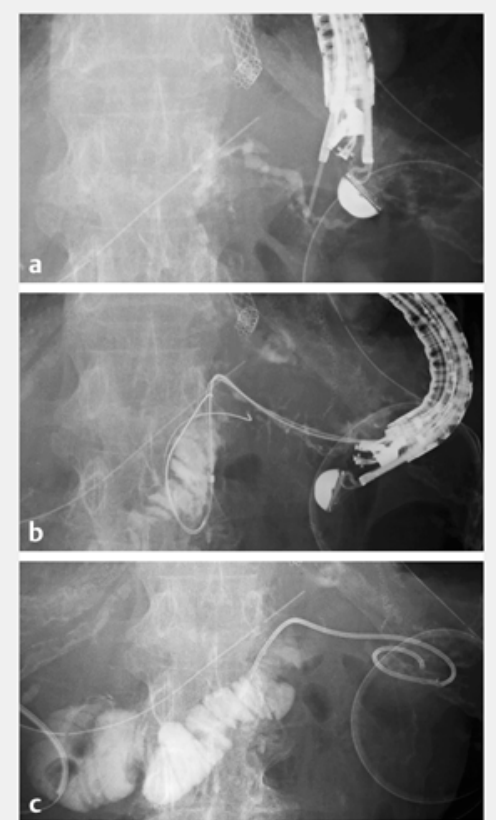

Fig. 3 Endoscopic ultrasound-guided transmural placement of a 5-Fr plastic stent for the non-dilated pancreatic duct. a Endoscopic ultrasound-guided access to the main pancreatic duct using a 19-gauge needle. Pancreatography delineated the non-dilated pancreatic duct with a diameter of $1.6 \mathrm{~mm}$. A percutaneous catheter is also shown. $\mathbf{b}$ We passed a 0.025 -inch guidewire into the jejunum. Using a double-lumen catheter, we additionally inserted a 0.035 -inch guidewire, which was utilized to stabilize the scope position ("double guidewire technique"). c Placement of a 5-Fr stent across the pancreaticojejunostomy anastomotic stricture. 


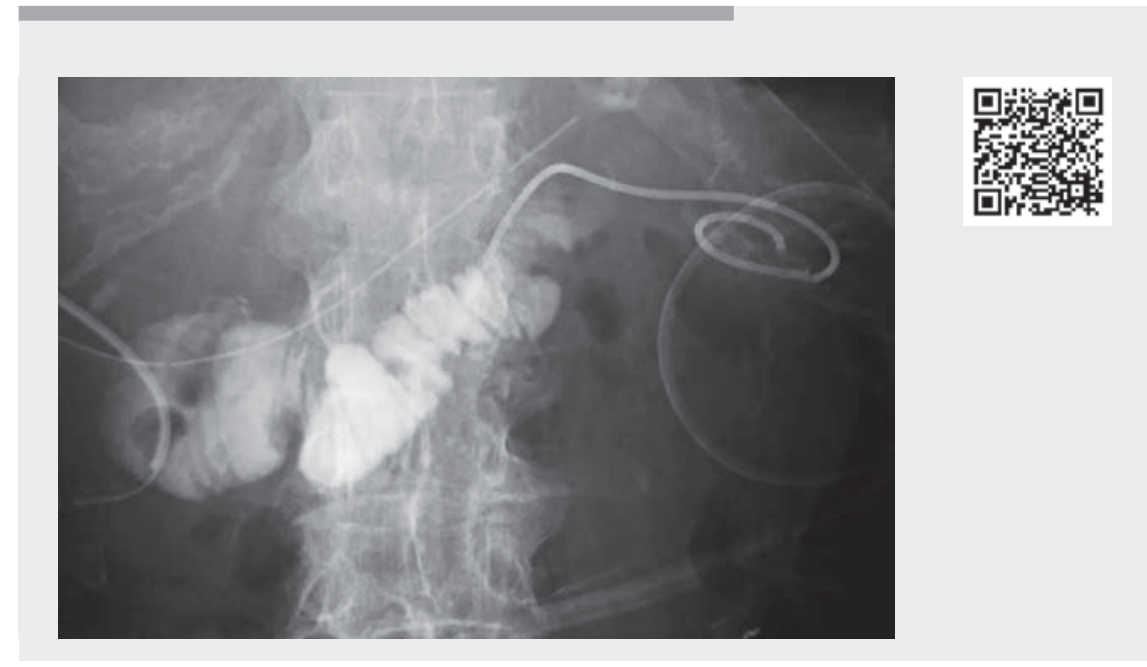

$\checkmark$ Video 1 Endoscopic ultrasound-guided transmural placement of a 5-Fr plastic stent for a non-dilated pancreatic duct.

The authors

Dosuke Iwadate ${ }^{1}$, Yousuke Nakai ${ }^{1,2} \odot$, Tsuyoshi Hamada ${ }^{1}$, Takao Itoi $^{3}$, Kazuhiko Koike ${ }^{1}$

1 Department of Gastroenterology, Graduate School of Medicine, The University of Tokyo, Tokyo, Japan

2 Department of Endoscopy and Endoscopic Surgery, Graduate School of Medicine, The University of Tokyo, Tokyo, Japan

3 Department of Gastroenterology and Hepatology, Tokyo Medical University, Tokyo, Japan

\section{Corresponding author}

\section{Yousuke Nakai, MD}

Department of Endoscopy and Endoscopic Surgery, Graduate School of Medicine, The University of Tokyo, 7-3-1 Hongo, Bunkyo-ku, Tokyo 113-8655, Japan ynakai-tky@umin.ac.jp

\section{References}

[1] Kahaleh M, Artifon ELA, Perez-Miranda M et al. EUS-guided drainage: summary of therapeutic EUS consortium meeting. Endosc Ultrasound 2019; 8: 151-160

[2] Teoh AYB, Dhir V, Kida M et al. Consensus guidelines on the optimal management in interventional EUS procedures: results from the Asian EUS group RAND/UCLA expert panel. Gut 2018; 67: 1209-1228

[3] Itoi T, Kasuya K, Sofuni A et al. Endoscopic ultrasonography-guided pancreatic duct access: techniques and literature review of pancreatography, transmural drainage and rendezvous techniques. Dig Endosc 2013; 25: 241-252

[4] Matsunami Y, Itoi T, Sofuni A et al. Evaluation of a new stent for EUS-guided pancreatic duct drainage: long-term follow-up outcome. Endosc Int Open 2018; 6: E505E512

[5] Nakai Y, Kogure H, Koike K. Double-guidewire technique for endoscopic ultrasoundguided pancreatic duct drainage. Dig Endosc 2019; 31: 65-66

\section{Bibliography}

Endoscopy 2021; 53: E407-E408

DOI 10.1055/a-1333-0538

ISSN 0013-726X

published online 14.1.2021

(c) 2021. Thieme. All rights reserved.

Georg Thieme Verlag KG, Rüdigerstraße 14,

70469 Stuttgart, Germany

\section{ENDOSCOPY E-VIDEOS \\ https://eref.thieme.de/e-videos}

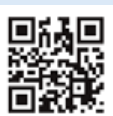

Endoscopy E-Videos is a free access online section, reporting on interesting cases and new

techniques in gastroenterological endoscopy. All papers include a high quality video and all contributions are freely accessible online.

This section has its own submission website at https://mc.manuscriptcentral.com/e-videos 